\title{
Editorial: Immunonutrient Supplementation
}

\author{
Thea Magrone ${ }^{1 * t}$, Alexander Haslberger ${ }^{2 \dagger}$, Emilio Jirillo ${ }^{1+}$ and Mauro Serafini ${ }^{3 \dagger}$ \\ ${ }^{1}$ Department of Basic Medical Sciences, Neuroscience and Sensory Organs, School of Medicine, University of Bari, Bari, \\ Italy, ${ }^{2}$ Department of Nutritional Sciences, University of Vienna, Vienna, Austria, ${ }^{3}$ Functional Foods and Metabolic Stress \\ Prevention Laboratory, Faculty of Bioscience and Technology for Food, Agriculture and Environment, University of Teramo, \\ Teramo, Italy
}

Keywords: polyphenols, fatty acid, vitamins, amino acids, iron

\section{Editorial on the Research Topic}

\section{Immunonutrient Supplementation}

Nowadays, food-related diseases are exponentially increasing worldwide. In fact, also in developing countries population has started consuming western diet. On these bases, overweight/obesity and diabetes represent a pandemy, thus, leading to associated diseases such as cardiac events, neurodegeneration, and cancer (1-3). Correct diets, e.g., Mediterranean diet (MeD), as well as nutrient supplementation represent a suitable approach to prevent and/or mitigate food-related diseases. In particular, among bioactive principles contained in foods, mostly polyphenols, have been investigated for their anti-oxidant, anti-inflammatory activities, even including DNA damage protection (4-9).

The present special issue entitled "Immunonutrient supplementation" encompasses a series of reviews and original articles which point out the modulatory effects of diet and of different

OPEN ACCESS

Edited and reviewed by: Willem Van Eden,

Utrecht University, Netherlands

*Correspondence: Thea Magrone thea.magrone@uniba.it

${ }^{\dagger}$ These authors have contributed equally to this work

Specialty section:

This article was submitted to

Nutritional Immunology,

a section of the journal

Frontiers in Nutrition

Received: 10 October 2019 Accepted: 18 November 2019 Published: 03 December 2019

Citation:

Magrone T, Haslberger A, Jirillo E and Serafini M (2019) Editorial:

Immunonutrient Supplementation.

Front. Nutr. 6:182.

doi: 10.3389/fnut.2019.00182 nutrients (polyphenols, amino acids, unsaturated fatty acids, vitamin D, and iron, respectively) on the immune response.

Ruiz-Leòn et al. have reviewed the principles of immune nutrition in relation to atherosclerosis development. MeD, for its content in bioactive compounds, has been associated to prevention or attenuation of atheroma inflammation. Here, Authors have analyzed the molecular mechanisms related to the in vivo protective actions of $\mathrm{MeD}$.

$\mathrm{Wu}$ et al. have reviewed the efficacy of interventions with unsaturated fatty acids, micronutrients, functional foods and tea derivatives on the immune function. Despite controversial results, there is strong evidence that all above mentioned principles play a protective role in autoimmune and inflammatory disorders also reducing infections.

Campbell et al. have reported the effects of two polyphenols, carnosol and curcumin, on the metabolism of dendritic cells (DCs). Metabolic regulation of DCs exerted by these polyphenols seems to be related to AMP-Activated Protein Kinase (AMPK) activation, which leads to the inhibition of mTOR pathway in lipopolysaccharide-primed DCs. In addition, activation of AMPK induces Heme Oxygenase-1 (HO-1), which, in turn, controls maturation, and function of human DCs.

Zhang et al. have studied the effects of Inonotus sanghuang polyphenols on the interaction between macrophages and adipocytes. Results show that these polyphenols are able to decrease chronic inflammation in adipose tissue, suppressing the cross talk between macrophages, and adipocytes.

Tuyaerts et al. have reported the effects of dietary curcumin ( $2 \mathrm{~g} /$ day for 2 weeks $)$ in seven endometrial carcinoma (EC) patients. During this clinical trial, several inflammatory biomarkers were measured, even including COX-2 and frequency of T cells, DCs, natural killer cells and myeloid-derived suppressor cells. In addition, quality of life (QoL) questionnaires were completed 
by patients at the start and the end of treatment. Authors conclude that this treatment does not lead to significant modifications of all parameter analyzed as well as of QoL.

Wang et al. have evaluated the effects of naringenin, a polyphenol, on $\mathrm{CD} 4+\mathrm{T}$ cells in a model of experimental autoimmune encephalomyelitis (EAE). Among major effects exerted by naringenin, inhibition of differentiation of CD4+ cells to Th1 and Th17 cells, decrease of Th17 cells and promotion of T regulatory (Treg) cell polarization have been reported. Then, all these activities would explain the beneficial effects of naringenin in preventing/mitigating EAE.

Azam et al. have reviewed the effects of polyphenols in the treatment of neurodegenerative diseases. Special emphasis has been placed on the ability of various polyphenols to dampen overexpression of inflammatory mediators interrupting the Tolllike receptor (TLR)-4/NF- $\mathrm{B} / \mathrm{STAT}$ pathway in microglia and macrophages. In the same direction, other polyphenols can decrease neuronal apoptosis, regulating the TLR-4/MyD88/NF$\kappa \mathrm{B}$ signaling. Therefore, modulation of TLR functions by polyphenols may represent a novel therapeutical tool in the treatment of neurodegeneration.

Lee et al. have reported on the effects of L-arginine and Lcitrulline supplementation on rat Treg cells. Male infantile rats received L-arginine or L-citrulline $(200 \mathrm{mg} / \mathrm{kg} /$ day i.p. $)$ over postnatal day 8 to day 14 . Both amino acids increased interleukin (IL)-10 release, while enhancing SIRT-1 expression. Only in the case of L-citrulline increase in the transforming growth factor (TGF)- $\beta 1$ and FoxP3 expression was noted. In conclusion, these amino acids have the ability to induce a tolerogenic pathway, thus, favoring anti-inflammatory activities under pathological conditions.

Zhang et al. have evaluated the effects of dietary Ltryptophan treatment on the Chinese mitten crab, Eriochier (E.) sinensis under cheliped autotomy stress. In treated individuals, mortality decreased with an increase in total hemocyte count, hemocyanin and glutathione (GSH) content and GSH peroxidase. Furthermore, increase in phagocytic rate and antioxidant activity was observed. These data were in agreement with the higher expression of anti-bacterial related protein genes. Taken together, these results indicate the ability of polyphenols to increase survival of E. sinensis under cheliped autotomy stress.

Machado et al. have demonstrated the ability of dietary methionine to improve immune and inflammatory responses and disease resistance in European sea bass (Dicentrarchus labrax). Then, following bacterial challenge a higher survival was observed in comparison to untreated fish, thus, suggesting a reinforcement of immune response after 4 weeks of methionine treatment, thus, supporting the anti-bacterial activity.

Xia et al. have summarized the mechanisms of betaine in IL-1 $\beta$ production release. This compound, which is a critical nutrient for mammal health, inhibits IL-1 $\beta$ release blocking exocytosis of IL-1 $\beta$ containing secretory lysosomes, thus, reducing shedding of IL- $1 \beta$ containing plasma membrane microvesicles. Then, these mechanisms reduce the passive efflux of IL-1 $\beta$ through plasma membrane in the course of pyroptotic cell death, representing a therapeutical tool in the course of IL-1 $\beta$ associated-inflammatory disease.

Saika et al. have reviewed the effect of lipid metabolites in the host and the participation of intestinal bacteria in this process. In particular, the role of metabolites from omega- 3 fatty acids, such as resolvins, protectins, and marensins has been described. Special emphasis has been placed on the metabolites of 17, 18-epoxyeicosatetraenoic acid, which exert anti-allergic and anti-inflammatory activities.

Goncalves-Mendes et al. have conducted a trial investigating the effects of vitamin D supplementation on deficient elderly persons in relation to influenza vaccination. Vitamin D supplementation has been shown to trigger elevated plasma levels of TGF- $\beta$ in response to influenza vaccination, thus, polarizing the immune response toward a tolerogenic pathway. No enhancement of antibody production to influenza vaccine was observed.

Dufrusine et al. have analyzed the influence of iron on the 5-lipoxygenase (LOX) trafficking and human macrophage activation. Results indicate that iron regulates the biological activity of 5-LOX in macrophages, enhancing its ability to bind to nuclear membranes. In relevance to this effect, iron overloading induced an increased expression of IL-6 in macrophages which was abolished by pre-treating cells with the iron-chelating agent deferoxamine.

As overall, the manuscripts have discussed different aspects related to immunonutrient supplementation, ranging from in vitro, ex vivo and human studies, highlighting the complexity, and the multi-faced aspects of the interactions between nutrient supplementation and immune function. Despite more research is needed, we think that this special issue should allow readers to increase their knowledge on the beneficial and sometimes adverse effects related to the role of nutrient supplementation on immune function.

\section{AUTHOR CONTRIBUTIONS}

All authors listed have made a substantial, direct and intellectual contribution to the work, and approved it for publication.

\section{FUNDING}

TM was a recipient of the grant Intervento cofinanziato dal Fondo di Sviluppo e Coesione 2007-2013-APQ Ricerca Regione Puglia Programma regionale a sostegno della specializzazione intelligente e della sostenibilità sociale ed ambientale-FutureInResearch. This study was supported by grants from the Italian Ministry of Education and Research (Proalifun project PON02 00186 2937475) as well as institutional grants from the University of Bari Aldo Moro. 


\section{REFERENCES}

1. Toti E, Di Mattia C, Serafini M. Metabolic food waste and ecological impact of obesity in FAO world's region. Front Nutr. (2019) 6:126. doi: 10.3389/fnut.2019.00126

2. Setayesh T, Mišík M, Langie SAS, Godschalk R, Waldherr M, Bauer T, et al. Impact of weight loss strategies on obesity-induced DNA damage. Mol Nutr Food Res. (2019) 63:e1900045. doi: 10.1002/mnfr.201900045

3. Magrone T, Jirillo E, Spagnoletta A, Magrone M, Russo MA, Fontana S, et al. Immune profile of obese people and in vitro effects of red grape polyphenols on peripheral blood mononuclear cells. Oxid Med Cell Longev. (2017) 2017:9210862. doi: 10.1155/2017/9210862

4. Hantikainen E, Grotta A, Serafini M, Trolle Lagerros Y, Nyren O, Ye W, et al. Dietary non-enzymatic antioxidant capacity and the risk of myocardial infarction: the Swedish National March Cohort. Int J Epidemiol. (2018) 47:1947-55. doi: 10.1093/ije/dyy220

5. Setayesh T, Nersesyan A, Mišík M, Noorizadeh R, Haslinger E, Javaheri T, et al. Gallic acid, a common dietary phenolic protects against high fat diet induced DNA damage. Eur J Nutr. (2019) 58:2315-26. doi: 10.1007/s00394-018-1782-2

6. Magrone T, Spagnoletta A, Bizzoca A, Russo MA, Jirillo E, Gennarini G. Polyphenol effects on splenic cytokine response in post-weaning contactin 1-overexpressing transgenic mice. Molecules. (2019) 24:E2205. doi: 10.3390/molecules24122205
7. Picocci S, Bizzoca A, Corsi P, Magrone T, Jirillo E, Gennarini G. Modulation of nerve cell differentiation: role of polyphenols and of contactin family components. Front Cell Dev Biol. (2019) 7:119. doi: 10.3389/fcell.2019.00119

8. Magrone T, Romita P, Verni P, Salvatore R, Spagnoletta A, Magrone M, et al. In vitro effects of polyphenols on the peripheral immune responses in nickel-sensitized patients. Endocr Metab Immune Disord Drug Targets. (2017) 17:324-31. doi: 10.2174/1871530317666171003161314

9. Magrone T, Spagnoletta A, Salvatore R, Magrone M, Dentamaro F, Russo MA, et al. Olive leaf extracts act as modulators of the human immune response. Endocr Metab Immune Disord Drug Targets. (2018) 18:8593. doi: 10.2174/1871530317666171116110537

Conflict of Interest: The authors declare that the research was conducted in the absence of any commercial or financial relationships that could be construed as a potential conflict of interest.

Copyright (c) 2019 Magrone, Haslberger, Jirillo and Serafini. This is an open-access article distributed under the terms of the Creative Commons Attribution License (CC $B Y)$. The use, distribution or reproduction in other forums is permitted, provided the original author(s) and the copyright owner(s) are credited and that the original publication in this journal is cited, in accordance with accepted academic practice. No use, distribution or reproduction is permitted which does not comply with these terms. 